\title{
Detection of Trace Amounts of Toxic Metals in Environmental Samples by Laser-excited Atomic Fluorescence Spectrometry*
}

\section{Invited Lecture}

\author{
Mikhail A. Bolshov, $\dagger$ Vsevolod G. Koloshnikov and Sergei N. Rudnev \\ Institute of Spectroscopy, USSR Academy of Sciences, 142092 Troitzk, Moscow Region, Russia \\ Claude F. Boutron and Ursula Görlach \\ Laboratoire de Glaciologie et Geophysique de l'Environnement du CNRS, Domaine Universitaire, 2, rue \\ Moliere, B.P. 96, 38402 St. Martin d'Heres Cedex, France \\ Clair C. Patterson \\ Division of Geological and Planetary Sciences 170-25, California Institute of Technology, Pasadena, CA \\ 91125, USA
}

\begin{abstract}
Results for the direct determination of trace amounts of $\mathrm{Pb}$ and $\mathrm{Cd}$ in Antarctic and Greenland ancient ice and recent snow by laser-excited atomic fluorescence spectrometry (LEAFS) are presented. The whole procedure starting from field sampling, mechanical decontamination of the samples in an ultra-clean laboratory and final analysis of the decontaminated samples is described. The measured concentrations varied in the ranges $0.1-3$ $\mathrm{pg} \mathrm{ml}^{-1}$ for $\mathrm{Cd}$ and $0.3-30 \mathrm{pg} \mathrm{ml}^{-1}$ for $\mathrm{Pb}$. The results for direct analysis by LEAFS agree favourably with those obtained by isotope dilution mass spectrometry and electrothermal atomic absorption spectrometry, which require time-consuming pre-treatment and pre-concentration stages.
\end{abstract}

Keywords: Trace amounts of toxic metals; laser-excited atomic fluorescence spectrometry; Antarctic and Greenland ice and snow; direct analysis

Over the last two decades there has been a continuing increasing interest in the investigation of the concentrations of toxic heavy metals (such as $\mathrm{Pb}, \mathrm{Cd}, \mathrm{Hg}$ and $\mathrm{Bi}$ ) in the environment. It is well known that human industrial activities have strongly modified the natural occurrence of these metals. Correct estimation of the difference between the natural (pre-industrial) and modern heavy metal content of the environment is of great scientific interest. The best approach to the problem is the investigation of toxic metal occurrences in the well preserved dated snow and ice layers deposited in the remote Antarctic and Greenland ice sheets. ${ }^{1-3}$ This is indeed a unique way to reconstruct the past natural tropospheric cycles of these metals and to assess their recent alteration by man in both hemispheres. ${ }^{4,5}$

Despite the growing interest, there are at present few reliable data for the $\mathrm{Pb}, \mathrm{Cd}$ and $\mathrm{Zn}$ contents in Antarctic and Greenland ice and snows because the minimum concentrations of these metals to be measured are extremely low (down to $0.3 \mathrm{pg} \mathrm{ml}^{-1}$ of $\mathrm{Pb}$ and less than $0.1 \mathrm{pg}$ $\mathrm{ml}^{-1}$ of $\mathrm{Cd}$ ). Such low concentrations manifest a serious challenge for a complete analytical project, starting from field sampling, then transportation, sample pre-treatment and the final analysis. The great difficulties of maintaining the highest levels of clean and uncontaminated conditions at every stage of the project were the reason for a large number of erroneous results being published at the very beginning of the exercise.

Even with the cleanest field sampling procedures most samples, especially deep ice cores, are contaminated on the outside. Reliable and accurate results could only be obtained after developing efficient ultra-clean procedures to decontaminate the samples. ${ }^{2,6,7}$ The decontaminated

\footnotetext{
* Presented at the XXVII Colloquium Spectroscopicum Internationale (CSI), Bergen, Norway, June 9-14, 1991.

+ To whom correspondence should be addressed.
}

samples must then be analysed using ultra-clean and ultrasensitive techniques.

Up until the last 2-3 years, the analytical techniques which had been used for the final analysis were either isotope dilution mass spectrometry (IDMS) ${ }^{1,2,6}$ or electrothermal atomic absorption spectrometry (ETAAS). ${ }^{3,7,8} \mathrm{Un}$ fortunately, both techniques are not sufficiently sensitive for direct measurements of the decontaminated samples. For IDMS a complicated chemical pre-treatment and large sample volumes $(30-500 \mathrm{ml})$ are required to extract a sufficient amount of analyte for the final analysis. For ETAAS, a pre-concentration step and large sample volumes (30-100 $\mathrm{ml})$ are also necessary.

The ultra-sensitive technique of laser-excited atomic fluorescence spectrometry (LEAFS) with electrothermal atomization offered a very promising alternative for the direct determination of toxic metals at and below the pg ml-1 level. The first measurements of $\mathrm{Pb}^{9}$ and $\mathrm{Cd}^{10}$ in Antarctic and Greenland ice and snows demonstrated the great potential of LEAFS as the analytical technique eventually used in the programme for monitoring toxic metals in ancient ice and snows.

Results of an international collaboration between scientists from France, the USA and USSR in the direct determination of $\mathrm{Pb}$ and $\mathrm{Cd}$ in Antarctic and Greenland ancient ice and recent snows are presented.

\section{Experimental}

\section{Samples and Reagents}

The samples analysed for the $\mathrm{Pb}$ and $\mathrm{Cd}$ contents were 14 sections of the $905 \mathrm{~m}$ Dome C deep Antarctic ice core, 6 sections of the $2083 \mathrm{~m}$ Vostok deep ice core and 18 samples of fresh snow collected on a precipitation event basis at Dye 3 station, South Greenland. The Dome C core was collected by thermal drilling at the French station Dome $\mathrm{C}$ in a dry 
hole without a wall retaining liquid. It covers the past 40000 years BP. The core from the Soviet Antarctic station at Vostok was thermally drilled in a hole filled with a wall retaining liquid (kerosene). It covers the past 155000 years BP.

All these core sections were transported frozen in double, sealed, polyethylene bags from the Antarctic to Patterson's clean laboratory at the California Institute of Technology (Caltech, Division of Geological and Planetary Sciences, Pasadena, CA, USA). The sections were about $10 \mathrm{~cm}$ in diameter and $15-30 \mathrm{~cm}$ in length. They were decontaminated inside the Caltech clean laboratory by mechanically chiselling successive veneers of ice (each $6-10 \mathrm{~mm}$ thick) in progression from the outside to the interior of the core using ultra-clean stainless-steel chisels. The whole procedure was performed on a cooled, double-walled, nitrogenflushed, ultra-clean polyethylene tray. The procedure has been described in detail elsewhere. ${ }^{6}$ The remaining inner cores were $2-4 \mathrm{~cm}$ in diameter.

The chiselled ice from a particular veneer (or inner core) was allowed to melt overnight at room temperature, in an ultra-clean conventional polyethylene beaker. The melted samples were then acidified to be $0.1 \%$ in $\mathrm{HNO}_{3}$ using ultrapure $\mathrm{HNO}_{3}$ prepared at the National Institute of Standards and Technology (NIST), Gaithersburg, MD, USA. The acidified solutions were allowed to stand for $2 \mathrm{~h}$, then $50-100 \mathrm{ml}$ aliquots were transferred into $250 \mathrm{ml}$ preconditioned polyethylene bottles, packed inside acid cleaned polyethylene bags and immediately frozen. Specific subsamples of these prepared samples were then analysed at Caltech by IDMS. The residual samples were then transported frozen to the Laboratoire de Glaciologie et Geophysique de l'Environnement (LGGE), France.

Inside the LGGE clean laboratory, the residual samples were allowed to melt at room temperature and $5-10 \mathrm{ml}$ subaliquots were transferred into $30 \mathrm{ml}$ preconditioned polyethylene bottles and packed inside acid cleaned polyethylene bags. These sub-aliquots were then transported frozen to the Institute of Spectroscopy (ISAN), USSR.

All of the polyethylene beakers and bottles used for pretreatment and storage of the ice samples and for the synthetic standards had been previously cleaned both at Caltech and at the LGGE clean laboratories. The cleaning procedures were similar to those reported in refs. 2, 9 and 11 and described in detail elsewhere. ${ }^{12}$

Aqueous standard solutions used in the experiments were synthetic, acidified $\left(0.1 \%\right.$ NIST $\left.\mathrm{HNO}_{3}\right)$, multi-elemental standards. These standards contained 19 elements according to typical elemental concentration ratios expected in the Antarctic ice. They were prepared in the LGGE clean laboratory from Baker or Fisher certified atomic absorption standards ( $1 \mathrm{mg} \mathrm{ml}^{-1}$ solutions). The procedure for the preparation of the standards has been described elsewhere ${ }^{9}$ and differed in some details from the typical procedure of successive dilutions. The concentrations of the standards used in the LEAFS measurements varied in the 1-250 $\mathrm{pg} \mathrm{ml} \mathrm{m}^{-1}$ range for $\mathrm{Pb}$ and $0.1-25 \mathrm{pg} \mathrm{ml}^{-1}$ range for $\mathrm{Cd}$.

\section{Apparatus}

Ancient Antarctic ice and recent snows were analysed using the laser atomic fluorescence analytical spectrometer (LAFAS-1) instrument designed and constructed at ISAN. A detailed description of the LAFAS- 1 has been given elsewhere, ${ }^{13}$ hence, only a brief description of the main units of the spectrometer will be given here.

\section{Radiation source}

Tunable dye lasers (DL) and the associated optical harmonics have been the most widely used sources for LEAFS so far. In the LAFAS-1 instrument, the DL was pumped by
Table 1 Typical parameters of the DL and SHG pulses (for a pulse energy of the pumping $\mathrm{XeCl}$ laser of $10 \mathrm{~mJ}$ )

$\begin{array}{lcc}\text { Parameter } & \mathrm{Pb} & \mathrm{Cd} \\ \text { Dye laser } & \text { Rhodamine } & \text { Coumarine } 47 \\ \text { Energy/mJ } & 0.7 & 0.8 \\ \text { Duration/ns } & 10 & 10 \\ \text { Power } / \mathrm{kW} & 70 & 80 \\ \text { Second harmonic } & \mathrm{KDP} & \mathrm{KB5} \\ \text { Energy } / \mu \mathrm{J} & 25 & 2 \\ \text { Duration/ns } & 8 & 8 \\ \text { Power } / \mathrm{kW} & 3 & 0.25\end{array}$

a $\mathrm{XeCl}$ excimer laser with a moderate pulse energy of 10 $\mathrm{mJ}$, with a pulse duration of $10 \mathrm{~ns}$ and repetition frequency of up to $25 \mathrm{~Hz}$.

The oscillator-amplifier scheme of the transversepumped DL was used. The wavelength of the DL was tuned and stabilized by the computer-controlled original grating assembly and control unit. The time required for setting a wavelength was $40 \mathrm{~ms}$. The range of angle rotation of the grating controlled by the electrodynamic drive was $2^{\circ}$. This range is sufficient to cover the entire tuning range of a particular dye.

Tunable ultraviolet radiation below $300 \mathrm{~nm}$ was obtained by second harmonic generation (SHG) of the DL radiation in non-linear crystals. Two types of crystals were used: KDP (40 $\mathrm{mm}$ in length, $15 \times 30 \mathrm{~mm}^{2}$ cross-section) for the cletermination of $\mathrm{Pb}$ and KB5 $\left(17 \mathrm{~mm}\right.$ in length, $5 \times 8 \mathrm{~mm}^{2}$ cross-section) for the determination of $\mathrm{Cd}$. The parameters of the DL and SHG radiation for the two analytes are listed in Table 1.

Lead atoms were excited at the $283.3 \mathrm{~nm}$ line and directline fluorescence was recorded at $405.8 \mathrm{~nm}$. As the structure of the electronic levels of the $\mathrm{Cd}$ atoms does not allow fluorescence to be recorded at any shifted line, the resonance scheme of $\mathrm{Cd}$ excitation and recording at the strongest line at $228.8 \mathrm{~nm}$ was used.

\section{Atomizer}

In the LAFAS-1 instrument, electrothermal atomization of the sample was used. The samples could be atomized both in a controlled inert atmosphere or under vacuum. Up to 50 $\mu l$ of the sample can be introduced into a graphite cup pressed between the graphite electrodes. In the experiments with $\mathrm{Pb}$, laboratory-made and pyrolytic graphite coated graphite cups were used, whereas in the experiments with Cd, Ringsdorff pyrolytic graphite coated graphite cups were used. The latter proved to be cleaner and produced more stable signals, with lifetimes approximately twice as long as the former. The temporal profile of the analytical signals was more reproducible with the Ringsdorff cups. The maximum temperature of the cup was $2700{ }^{\circ} \mathrm{C}$ and the temperature was controlled and stabilized by monitoring the radiation of the cup. The optimum heating programmes for $\mathrm{Pb}$ and $\mathrm{Cd}$ are listed in Table 2 .

The laser beam profile over the cup was shaped by a system of diaphragms and lenses in front of the input window of the chamber. The scattering of the laser radiation was a serious problem for the resonance fluorescence of $\mathrm{Cd}$. To minimize this scattering the beam formation system was improved in comparison with that described in ref. 13. The major changes were made in order to decrease the extent of the optical surfaces prior to the chamber and reduce the scattering of the laser beam at large angles. The improved optical scheme is shown in Fig. 1 and clescribed in detail in ref. 14. 
Table 2 Atomization programmes for $\mathrm{Pb}$ and $\mathrm{Cd}$

\begin{tabular}{|c|c|c|c|c|c|c|c|c|}
\hline \multirow[b]{2}{*}{ Step } & \multicolumn{2}{|c|}{$\begin{array}{l}\text { Temperature/ } \\
{ }^{\circ} \mathrm{C}\end{array}$} & \multicolumn{2}{|c|}{$\begin{array}{c}\text { Ramp rate/ } \\
{ }^{\circ} \mathrm{C} \mathrm{s}^{-1}\end{array}$} & \multicolumn{2}{|c|}{$\begin{array}{l}\text { Hold time/ } \\
\text { s }\end{array}$} & \multicolumn{2}{|c|}{$\begin{array}{l}\text { Argon flow rate } \\
1 \mathrm{~min}^{-1}\end{array}$} \\
\hline & $\mathrm{Pb}$ & $\mathrm{Cd}$ & $\mathrm{Pb}$ & $\mathrm{Cd}$ & $\mathrm{Pb}$ & $\mathrm{Cd}$ & $\mathrm{Pb}$ & $\mathrm{Cd}$ \\
\hline $\begin{array}{l}\text { Dry } \\
\text { Ash } \\
\text { Atomize } \\
\text { Clean } \\
\text { Cool }\end{array}$ & $\begin{array}{r}95 \\
600 \\
1600 \\
2000 \\
20\end{array}$ & $\begin{array}{r}90 \\
180 \\
1000 \\
1200 \\
20\end{array}$ & $\begin{array}{r}40 \\
80 \\
700 \\
700 \\
-\end{array}$ & $\begin{array}{r}30 \\
80 \\
500 \\
500 \\
-\end{array}$ & $\begin{array}{r}30 \\
10 \\
4 \\
5 \\
40\end{array}$ & $\begin{array}{r}210 \\
10 \\
4 \\
5 \\
50\end{array}$ & $\begin{array}{l}3 \\
3 \\
3 \\
0 \\
0\end{array}$ & $\begin{array}{l}6 \\
3 \\
3 \\
0 \\
0\end{array}$ \\
\hline
\end{tabular}

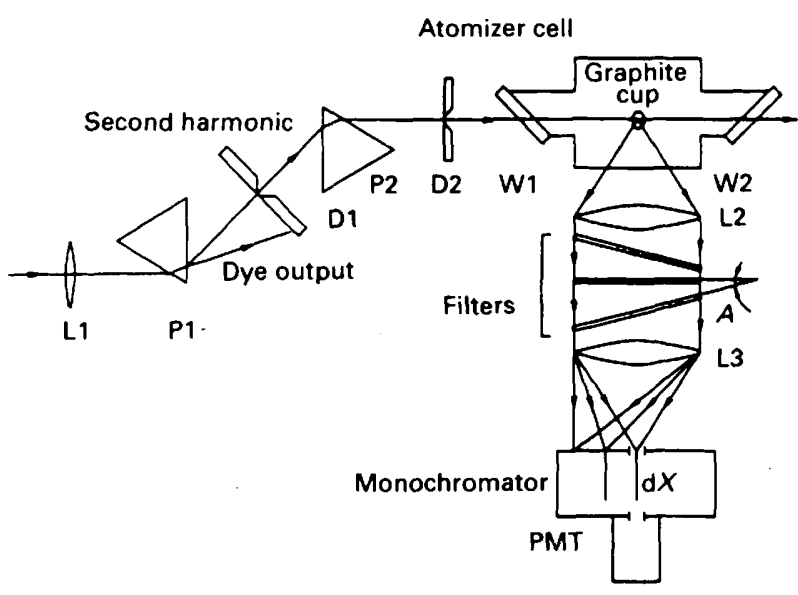

Fig. 1 Modified optical scheme of the LAFAS-1 spectrometer: L1-L3, lenses; P1 and P2, prisms; D1 and D2, diaphragms; W1, input window; and W2, output window

\section{Recording system}

Fluorescence photons were collected at an angle of $90^{\circ}$ on the entrance slit of the monochromator (relative aperture $1: 3.7$, reciprocal linear dispersion of $6.3 \mathrm{~nm} \mathrm{~mm}^{-1}$ ) by a telescopic system. Fluorescence was recorded by a photomultiplier tube, FEU-100, and a charge sensitive analogueto-digital converter (ADC). The ADC output numerical code was fed to the computer for further processing. Neutral light filters were used to attenuate the intensity of the fluorescence for high concentrations of analyte.

\section{Analytical methodology}

In order to reduce contamination of the standards and samples, the LAFAS-1 instrument was located inside a specially designed room supplied with filtered air. In addition, the atomizer, recording system, associated electronics and a special table covered with polyethylene film for the standards and samples were placed inside a clean. chamber. The ventilation system of the chamber provided high efficiency filtering of the air and a laminar vertical flow of clean air inside the chamber.

Both the samples and standards were introduced into the cup manually with a $20 \mu \mathrm{l}$ Eppendorf micropipette. Each new polypropylene tip of the micropipette was cleaned before the first use by dipping for $2-3 \mathrm{~min}$ into concentrated laboratory-reagent grade $\mathrm{HNO}_{3}$ followed by several consecutive rinsings with $1 \% \mathrm{HNO}_{3}$ (NIST, doubly distilled, diluted in LGGE ultra-pure water). In the course of the experiments, the tip was cleaned in three consecutive bottles of $1 \% \mathrm{HNO}_{3}$ before every sample insertion. Typically one tip was used for one working day for all the standards and samples, provided there was no accidental contamination.

\section{Results}

\section{Calibration of the LAFAS-1 Instrument}

Detailed calibration of the LAFAS-1 instrument was performed using the synthetic acidified standards described above. The following sets of standards were used: $1,2.5,5$, $10,25,50,100$ and $250 \mathrm{pg} \mathrm{ml}^{-1}$ of $\mathrm{Pb}$ and $0.1,0.25,0.5$, $1.0,2.5,5.0,10.0$ and $25.0 \mathrm{pg} \mathrm{ml} \mathbf{~}^{-1}$ of $\mathrm{Cd}$. Each standard was measured 2-3 times. Full sets of the analytical signals measured (numerical values) have been published elsewhere. 9.10

The regression lines were constructed for both analytes by the least-squares method in the form

$$
\log A_{i}=\log a+b \log C_{i}
$$

where $A_{i}$ is the analytical signal (ADC code, arbitrary units), $C_{i}$ is the analyte concentration in the $i$ th standard and $b$ is the slope of the regression line. The limit of detection (LOD) was obtained for both analytes by extrapolation of the regression line to three standard deviations of the background. The parameters of the regression lines and LODs for $\mathrm{Pb}$ and $\mathrm{Cd}$ are listed in Table 3. The concentration of $\mathrm{Pb}$ in LGGE ultra-pure water was found, from the regression line, to be $0.28 \mathrm{pg} \mathrm{ml}^{-1}$, which is in excellent agreement with the value of $0.27 \mathrm{pg} \mathrm{ml}^{-1}$ previously determined by IDMS. The concentrations of $\mathrm{Pb}$ in the Caltech and Cd in the LGGE and Caltech ultra-pure waters were found to be below the LODs for the LAFAS-1 instrument.

\section{Outer-Inner Profiles of the Deep Ice Cores}

In spite of all the precautions taken during field sampling, the outermost veneers of all the core sections were contaminated to some extent during drilling and packaging. To obtain the true values of the toxic metals content of a particular ice section, all veneers of the section should be analysed. If an 'outer-inner' profile exhibits a plateau for the analyte concentration from the second or third layer to the inner core, it could be stated that the surface contamination did not penetrate to the central part of the section. The plateau concentration then represents the metal concentration in that section of the deep ice core. However, if the profile exhibits a continuous decrease in the concentration from the outside to the central part, the inner core concentration must be regarded as the upper limit. Profiles for the Cd content were measured using the LAFAS-1 instrument for 10 of the 14 sections of Dome $C$ core and for all 6 sections of the Vostok core. Two types of Cd profiles,

Table 3 Parameters for the regression lines and LODs for $\mathrm{Pb}$ and $\mathrm{Cd}\left(\log a\right.$ values for $C_{i}$ in $\left.\mathrm{pg} \mathrm{ml^{-1 }}\right)$

$\begin{array}{cccc}\text { Analyte } & \log a & b & \mathrm{LOD} / \mathrm{pg} \mathrm{m} \mathrm{m}^{-1} \\ \mathrm{~Pb} & 2.36 & 0.92 & 0.18 \\ \mathrm{Cd} & 3.71 & 1.03 & 0.07\end{array}$




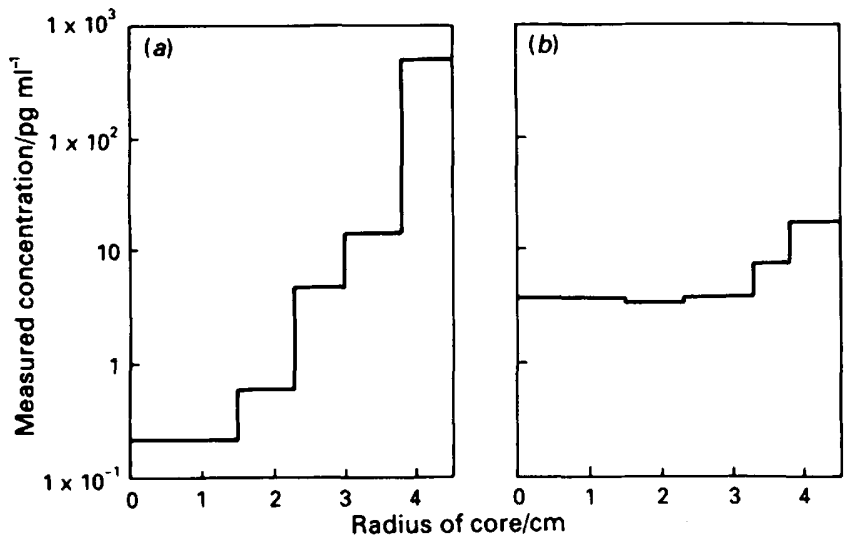

Fig. 2 External-internal profiles of $\mathrm{Cd}$ concentrations for the two deep ice core sections: $(a)$ Dome C, 172 m (3846 years BP); and (b) Vostok, $499 \mathrm{~m}$ (26200 years BP)

with and without plateaus are shown in Fig. 2. The same profiles have been measured for $\mathrm{Pb}$ previously by IDMS $^{6}$ and some of the results were checked with the LAFAS-1.

\section{Ancient Antarctic Ice Samples}

Initially, contamination caused by the chiselling procedure and from the ultra-pure $\mathrm{HNO}_{3}$ and the water, the walls of the bottles and beakers, the air inside the laboratory, etc., were carefully determined in numerous blank measurements. To do this an artificial ice core made by freezing Caltech ultra-pure water was chiselled and sub-divided using the same procedure as described above. Thus prepared blank samples were analysed for the $\mathrm{Pb}$ content by IDMS at Caltech and for the Cd content using LAFAS- 1 at ISAN. The blank values were found to be about 0.11 pg ml-1 for $\mathrm{Pb}$ and about $0.06 \mathrm{pg} \mathrm{ml}^{-1}$ for $\mathrm{Cd}$. All the determined concentrations of the analytes in ice samples were corrected for these blank values.

All of the measurements made using the LAFAS-1 instrument were made with sample volumes of $20 \mu \mathrm{l}$ for $\mathrm{Pb}$ and $50 \mu \mathrm{l}$ for $\mathrm{Cd}$. The full sets of the experimental data for both analytes have been published elsewhere., 90 The confidence intervals (CIs) for the measured concentrations were calculated using eqn. 8 from ref. 15 or eqn. (3) from ref. 9. For most samples the CI values (at the $95 \%$ confidence level) ranged from about 30 up to $50 \%$ of the measured concentration.

Variations in the $\mathrm{Pb}$ and $\mathrm{Cd}$ concentrations with depth in the Dome $\mathrm{C}$ and Vostok ice cores are shown in Figs. 3 and 4 , respectively. It should be noted that there is very good agreement between the IDMS and LEAFS data for $\mathrm{Pb}$. For most sections the results coincided to within the limits of experimental error, which strongly supports the accuracy obtainable with both analytical techniques.

The LAFAS-1 data for $\mathrm{Cd}$ are the first accurately measured values with estimated CIs for all sections of the Dome $\mathrm{C}$ and the Vostok ice cores. Previously published ${ }^{16}$ $\mathrm{Cd}$ concentrations for the Dome $\mathrm{C}$ provided only upper limits for many sections, because, even after preconcentration the Cd contents of these samples were below the LOD for ETAAS. The lowest concentration of $\mathrm{Cd}\left(0.10 \mathrm{pg} \mathrm{ml}^{-1}\right)$ was obtained for the $500.5 \mathrm{~m}$ Dome $C$ section (14000 years BP). For a $50 \mu \mathrm{l}$ sample volume this corresponds to only $5 \mathrm{fg}$ of $\mathrm{Cd}$ in the sample.

In Fig. 3 several data points (open circles) represent the Cd values that should be carefully checked at some future date. For these sections the 'outer-inner' profiles are not

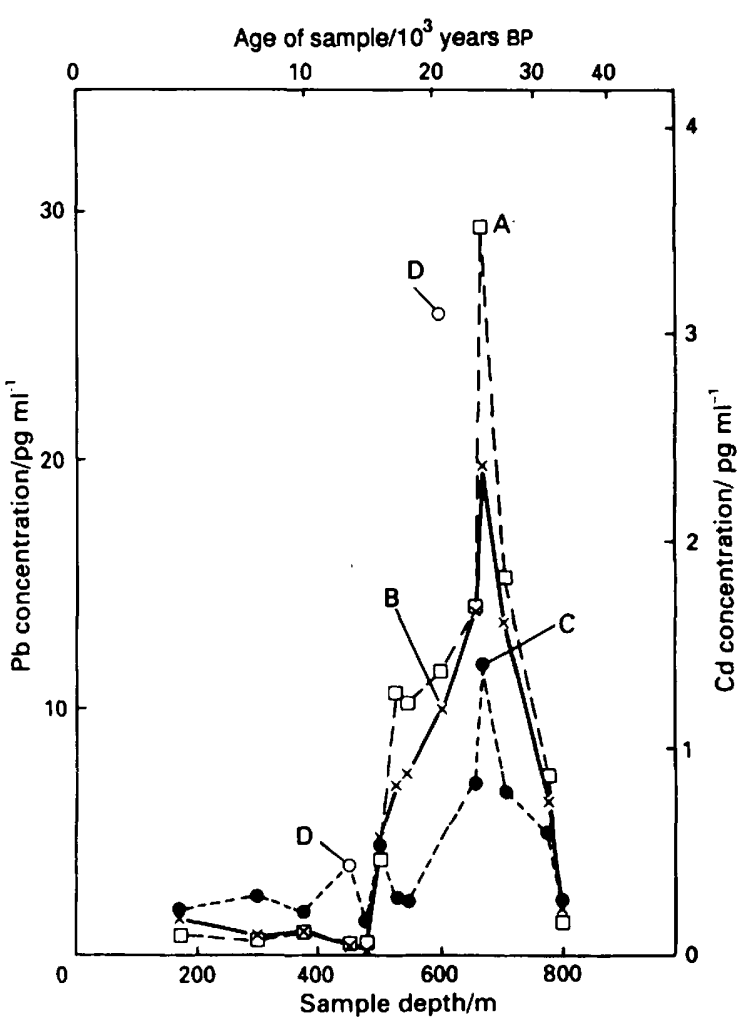

Fig. 3 Variations of the $\mathrm{Pb}$ and $\mathrm{Cd}$ concentrations in the Dome $\mathrm{C}$ deep ice core as a function of the age of the ice: $A$, IDMS Pb values; $\mathrm{B}$, LAFAS-1 Pb values; C, LAFAS-1 Cd values (sections with a concentration plateau); and D, LAFAS-1 Cd values (sections without a concentration plateau)

monotonic, as the $\mathrm{Cd}$ concentrations in inner cores are higher than in some of the outer layers. This could be due to possible contamination during sample pre-treatment and/ or sub-dividing of the samples. The result for the section at $502 \mathrm{~m}$ is particularly dubious as the $\mathrm{Cd}$ concentration in the inner core is $3.1 \mathrm{pg} \mathrm{ml}^{-1}$ but it is $0.6 \mathrm{pg} \mathrm{ml}^{-1}$ in the previous (sixth) layer. It should be pointed that the $\mathrm{Pb}$ concentration in this same $602 \mathrm{~m}$ section is fairly 'normal'.

Without this dubious point for $602 \mathrm{~m}$, the Dome $\mathrm{C}$ profile for Cd qualitatively matches the $\mathrm{Pb}$ profile. Matching of the profiles for the two analytes is even better for the Vostok ice core.

\section{Greenland Fresh Snow}

A comparative determination of $\mathrm{Cd}$ in Greenland fresh snow was carried out using the LEAFS and ETAAS techniques. Because of significant anthropogenic input, the Cd concentrations are relatively high, in the range $1-10$ pg ml$l^{-1}$ in recent Greenland snow. These Cd contents can be measured by ETAAS after preconcentration. ${ }^{17,18}$ The samples of fresh snow were collected on a precipitation event basis from January to August 1989 at Dye 3, South Greenland, as part of the 'Dye 3 Gas and Aerosol Sampling Program' of the US National Science Foundation. Eighteen samples of snow were analysed by LEAFS and ETAAS. The result of direct analyses using the LAFAS- 1 and the analysis of preconcentrated samples using a Perkin-Elmer 2380 spectrometer (HGA-500 graphite furnace, $50 \mu \mathrm{l}$, for $3 \times 50$ ipl injections) are listed in Table 4 . It can be seen that LAFAS-1 and ETAAS data are again in excellent agreement, which strongly supports the accuracy obtainable with both techniques. 


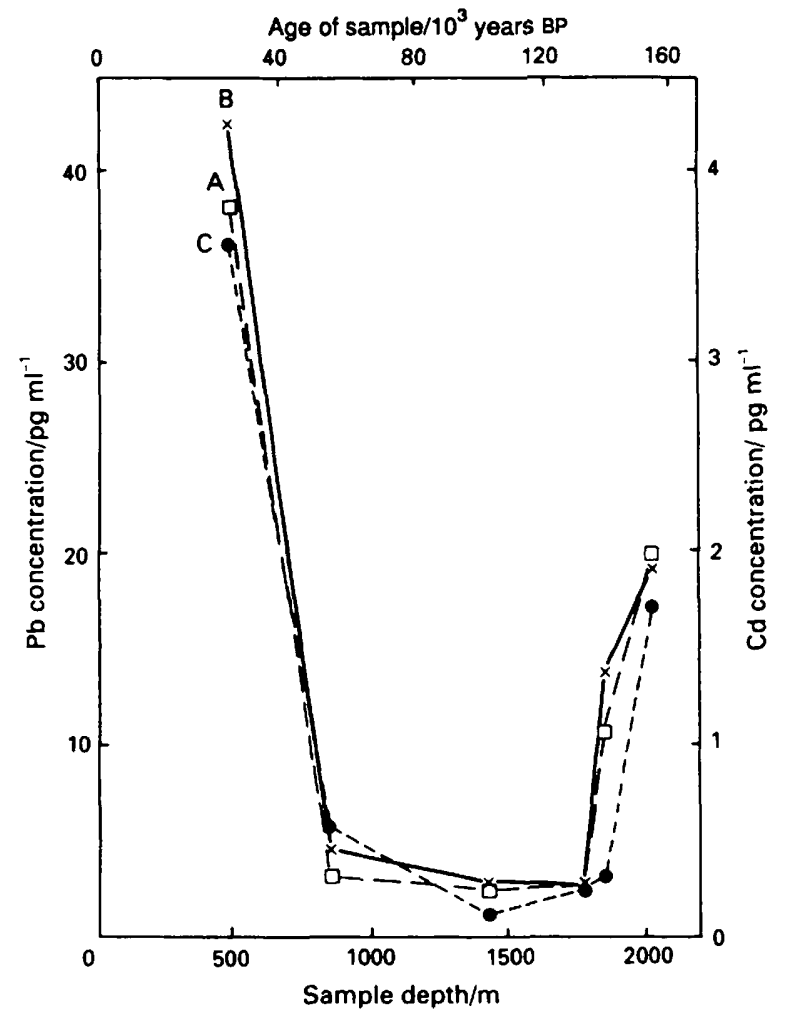

Fig. 4 Variations of the $\mathrm{Pb}$ and $\mathrm{Cd}$ concentrations in the Vostock deep ice core as a function of the age of the ice: $\mathrm{A}, \mathrm{IDMS} \mathrm{Pb}$ values; $B$, LAFAS-1 Pb values; and C, LAFAS-1 Cd values

\section{Discussion}

The sensitivity of the LEAFS technique is excellent, as it is several orders of magnitude better than IDMS and ETAAS for the determination of $\mathrm{Pb}$ and $\mathrm{Cd}$. For all samples measured, the results for both $\mathrm{Pb}$ and $\mathrm{Cd}$ using the LAFAS-1 instrument and by IDMS or ETAAS are in excellent agreement. It must, however, be emphasized again that the LAFAS-1 measurements required only $20 \mu \mathrm{l}$ of sample for the $\mathrm{Pb}$ and $50 \mu \mathrm{l}$ of sample for the $\mathrm{Cd}$

Table 4 Comparative determination of $\mathrm{Cd}$ in Greenland fresh snows by LEAFS ${ }^{10}$ and ETAAS $^{18}$ (with preconcentration)

\begin{tabular}{|c|c|c|}
\hline \multirow{2}{*}{$\begin{array}{l}\text { Sampling } \\
\text { date (1989) }\end{array}$} & \multicolumn{2}{|c|}{$\begin{array}{c}\text { Cd concentration } \\
( \pm \text { standard deviation, } n=3) / \mathrm{pg} \mathrm{ml} l^{-1}\end{array}$} \\
\hline & LAFAS-1 & ETAAS \\
\hline January 7 & $1.6 \pm 0.9$ & $1.4 \pm 0.4$ \\
\hline February 23 & $2.1 \pm 1.2$ & $4.0 \pm 0.6$ \\
\hline April 10 & $0.88 \pm 0.50$ & $1.0 \pm 0.3$ \\
\hline April 15 & $3.0 \pm 1.7$ & $4.2 \pm 0.6$ \\
\hline April 19 & $1.1 \pm 0.6$ & $1.5 \pm 0.3$ \\
\hline April 21 & $1.7 \pm 1.0$ & $2.0 \pm 0.4$ \\
\hline April 25 & $0.41 \pm 0.24$ & $0.2 \pm 0.2$ \\
\hline April 29 & $1.3 \pm 0.7$ & $1.7 \pm 0.4$ \\
\hline June 5 & $2.5 \pm 1.4$ & $2.9 \pm 0.5$ \\
\hline June 10 & $7.3 \pm 4.2$ & $8.9 \pm 1.0$ \\
\hline June is & $2.3 \pm 1.3$ & $2.4 \pm 0.4$ \\
\hline June 25 & $8.0 \pm 5.1$ & $14.5 \pm 1.4$ \\
\hline June 26 & $1.5 \pm 0.9$ & $2.4 \pm 0.4$ \\
\hline July 2 & $0.94 \pm 0.53$ & $0.9 \pm 0.4$ \\
\hline July 16 & $3.5 \pm 2.0$ & $4.2 \pm 0.6$ \\
\hline July 18 & $0.31 \pm 0.18$ & $0.2 \pm 0.2$ \\
\hline August 5 & $0.47 \pm 0.27$ & $0.6 \pm 0.4$ \\
\hline August 6 & $2.9 \pm 1.6$ & $3.1 \pm 0.5$ \\
\hline
\end{tabular}

determinations. On the other hand, for the IDMS measurements $50-200 \mathrm{ml}$ of sample and a difficult and timeconsuming chemical pre-treatment stage were required for analyses at the $\mathrm{pg} \mathrm{\textrm {ml } ^ { - 1 }}$ level. In addition, one sample analysis can take at least half a day. For the ETAAS measurements, $50 \mathrm{ml}$ of sample and time-consuming preconcentration were necessary.

In these first applications of the LEAFS technique to the direct determination of trace amounts of $\mathrm{Pb}$ and $\mathrm{Cd}$ in ancient ice and recent snow, the main goal was to compare the results with those obtained by IDMS or ETAAS for as large a concentration range as possible and for samples taken from different sections of deep ice cores and different geographic locations. There could have been a systematic difference as the speciation of the analytes may not have been the same during the different geologic epochs, Holocene, Last Glacial Maximum (LGM), Wisconcin and Last Interglacial. During this first stage of the project it was decided to analyse the maximum amounts of samples from different sections, but most samples were measured only once. Only very unexpected and dubious results for a number of samples (such as the Cd content in the $602 \mathrm{~m}$ Dome $\mathrm{C}$ section) were repeated two or three times. The small number of measurements caused the relatively wide CIs obtained (30-50\%). Obviously, much narrower CIs could be obtained in the future with more extensive sets of measurements.

The different sources of $\mathrm{Pb}$ in Antarctic ancient ice were carefully determined and discussed in previous work. ${ }^{6,19}$ It was shown that the main sources of atmospheric $\mathrm{Pb}$ are soil dust and volcano plumes. The contribution from the oceans is insignificant throughout the period studied. The time variations of the $\mathrm{Pb}$ concentration faithfully tracks variations in the soil dust $\mathrm{Pb}$ concentration, calculated from aluminium concentrations in ice, thus proving that most of the natural $\mathrm{Pb}$ in the global atmosphere originated from soil dust, during both the late Wisconsin (LGM) and the next to last ice age. The contribution to the $\mathrm{Pb}$ content from volcanoes, calculated from sulphate concentrations in the ice, was negligible during the late Wisconcin and next to last ice age but accounts for about half of the measured total $\mathrm{Pb}$ during the Holocene age.

A detailed interpretation of changes in Cd concentration in the Antarctic is given ref. 20.

These data for the $\mathrm{Pb}$ and $\mathrm{Cd}$ contents in deep ice cores confirm that prior to human industrial activities there were no excesses of the two toxic metals above that contributed by soil dust and volcanoes. Now more than $99 \%$ of $\mathrm{Pb}$ in the troposphere of the Northern Hemisphere originates from human activities. Anthropogenic Cd emissions to the atmosphere (about 7600 tonnes per year in 198321,22) are now surpassing natural $\mathrm{Cd}$ emissions from rocks and soils, sea-salt spray, volcanoes and biogenic sources (about 1300 tonnes per year). ${ }^{22}$

\section{References}

1 Murozumi, M., Chow, T. J., and Patterson, C. C., Geochim. Cosmochim. Acta, 1969, 33, 1247.

$2 \mathrm{Ng}, \mathrm{A}$., and Patterson, C. C., Geochim. Cosmochim. Acta, $1981,45,2109$.

3 Wolf, E. W., and Peel, D. A., Nature (London), 1985, 313, 535.

4 Peel, D. A., in The Environmental Record in Glaciers and Ice Sheets, ed. Oeschger, H., and Langway, C. C., Jr., Dahlem Konferenzen, Wiley, New York, 1989, p. 207.

5 Boutron, C. F., and Görlach, U., in Metal Speciation in the Environment, ed. Broekaert, J. A. C., Gücer, S., and Adams, F., Springer Verlag, Berlin, 1990, p. 137.

6 Boutron, C. F., and Patterson, C. C., Nature (London), 1986, 323, 222.

7 Wolf, E. W., and Peel, D. A., Ann. Glaciol., 1988, 10, 193. 
8 Wolf, E. W., and Peel, D. A., Ann. Glaciol., 1985, 7, 61

9 Bolshov, M. A., Boutron, C. F., and Zybin, A. V., Anal. Chem., $1989,61,1758$

10 Bolshov, M. A., Boutron, C. F., Ducroz, F. M., Görlach, U., Kompanetz, O. N., and Rudnev, S. N., Anal. Chim. Acta, 1991, 251, 169.

11 Boutron, C. F., and Patterson, C. C., Geochim. Cosmochim. Acta, 1983, 47, 1355.

12 Boutron, C. F., Fresenius J. Anal. Chem., 1990, 337, 482.

13 Apatin, V. M., Arkhangelskii B. V., Bolshov, M. A., Ermolov, V. V., Koloshnikov, V. G., Kompanetz, O. N., Kuznrtsov, N. I., Mikhailov, E. L., Shishkovskii, V. S., and Boutron, C. F., Spectrochim. Acta, Part B, 1989, 44, 253.

14 Bolshov, M. A., Hütsch, B., and Rudnev, S. N., J. Anal. At. Spectrom., 1992, 7, 1.

15 Bolshov, M. A., Dashin, S. A., Zybin, A. V., Koloshnikov, V. G., Mayorov, I. A., and Smirenkina, I. I., Zh. Anal. Khim., 1986, 41, 1862.
16 Batifol, F., Boutron, C. F., and de'Agelis, M., Nature (London), $1989,337,544$.

17 Görlach, U., and Boutron, C. F., in Heavy Metals in the Environment, ed. Vernet, J. P., CEP Consultants, Edinburgh, 1989 , p. 24.

18 Ducroz, F., Görlach, U., Jaffrezo, J. L., and Boutron, C. F., unpublished data.

19 Boutron, C. F., Patterson, C. C., Petrov, V. N., and Barkov, N. I., Atmos. Environ., 1987, 21, 1197.

20 Nriagu, J. O., and Pacyna, J. M., Nature (London), 1988, 333, 134.

21 Nriagu, J. O., Nature (London), 1989, 338, 47.

Paper 1/03030B

Received June 17, 1991 Accepted July 9, 1991 